\title{
IC97 Is a Novel Intermediate Chain of I1 Dynein That Interacts with Tubulin and Regulates Interdoublet Sliding
}

\author{
Maureen Wirschell, ${ }^{*}$ Chun Yang, ${ }^{+}$Pinfen Yang, ${ }^{+}$Laura Fox, ${ }^{*}$ \\ Haru-aki Yanagisawa, ${ }^{\ddagger}$ Ritsu Kamiya, ${ }^{\ddagger}$ George B. Witman, $\$$ Mary E. Porter,, \\ and Winfield S. Sale*
}

\author{
*Department of Cell Biology, Emory University School of Medicine, Atlanta, GA 30322; ${ }^{\dagger}$ Department of \\ Biology, Marquette University, Milwaukee, WI 53201; ‡Department of Biological Sciences, Graduate School of \\ Science, University of Tokyo, Tokyo 113-0033, Japan; §Department of Cell Biology, University of \\ Massachusetts Medical School, Worcester, MA 01655; and "Department of Genetics, Cell Biology and \\ Development, University of Minnesota, Minneapolis, MN 55455
}

Submitted April 8, 2009; Revised April 23, 2009; Accepted April 29, 2009

Monitoring Editor: Erika Holzbaur

\begin{abstract}
Our goal is to understand the assembly and regulation of flagellar dyneins, particularly the Chlamydomonas inner arm dynein called I1 dynein. Here, we focus on the uncharacterized I1-dynein IC IC97. The IC97 gene encodes a novel IC without notable structural domains. IC97 shares homology with the murine lung adenoma susceptibility 1 (Las1) protein-a candidate tumor suppressor gene implicated in lung tumorigenesis. Multiple, independent biochemical assays determined that IC97 interacts with both $\alpha$ - and $\beta$-tubulin subunits within the axoneme. I1-dynein assembly mutants suggest that IC97 interacts with both the IC138 and IC140 subunits within the I1-dynein motor complex and that IC97 is part of a regulatory complex that contains IC138. Microtubule sliding assays, using axonemes containing I1 dynein but devoid of IC97, show reduced microtubule sliding velocities that are not rescued by kinase inhibitors, revealing a critical role for IC97 in I1-dynein function and control of dynein-driven motility.
\end{abstract}

\section{INTRODUCTION}

Dyneins are minus-end-directed microtubule motors important for a variety of cellular functions, including membrane-bound organelle transport, assembly and orientation of the mitotic spindle, nuclear migration, assembly of the Golgi apparatus, and ciliary and flagellar motility. In the ciliary/flagellar axoneme, the outer and inner dynein arms convert the energy derived from ATP hydrolysis into microtubule sliding, which in turn drives flagellar beating and bending. Analysis using the model genetic organism Chlamydomonas reinhardtii has revealed that the inner arm dynein system is responsible for generation of the flagellar waveform - the size and shape of the flagellar bend (Brokaw and Kamiya, 1987; Kamiya, 2002; King and Kamiya, 2009). The inner dynein arms, of which there are at least seven isoforms (King and Kamiya, 2009), are heterogeneous in composition and structural arrangement on the axoneme, binding to the axoneme in precise locations to form part of a 96-nm repeating module along each doublet microtubule (Goodenough and Heuser, 1985; Piperno et al., 1990; Burgess et al., 1991; Mastronarde et al., 1992; Porter et al., 1992;

This article was published online ahead of print in $M B C$ in Press (http:/ /www.molbiolcell.org/cgi/doi/10.1091/mbc.E09-04-0276) on May 6, 2009.

Address correspondence to: Winfield S. Sale (win@cellbio. emory.edu).

Abbreviations used: bop, bypass of paralysis; FAP, flagellar associated protein; HC, heavy chain; IC, intermediate chain; LC, light chain; PKI, protein kinase inhibitor.
Nicastro et al., 2006; Bui et al., 2008). The two-headed I1 dynein isoform, also called dynein $f$, is distributed uniformly along the length of the axoneme as a triad structure located proximal to each radial spoke S1 (Nicastro et al., 2006; Porter and Sale, 2000; Wirschell et al., 2007).

I1 dynein is among the best characterized inner arm isoforms, containing two heavy chains ( $\alpha-\mathrm{HC}$ and $\beta-\mathrm{HC})$, three intermediate chains (IC138, IC140, and IC97-also termed IC110), and five known light chains (LC8, LC7a, LC7b, TcTex1, and TcTex2b) (Table 1; (Piperno et al., 1990; Myster et al., 1997; 1999; Harrison et al., 1998; Pazour et al., 1998; Perrone et al., 1998, 2000; Yang and Sale, 1998; DiBella et al., 2004a,b; Hendrickson et al., 2004). Recently, a new I1-dynein-associated protein, flagellar-associated protein (FAP)120, has been identified that interacts with IC138, LC7b, and IC97 (Ikeda et al., 2008; Bower et al., 2009). Multiple lines of evidence demonstrate that I1 dynein is an unusual dynein motor that plays a critical regulatory role in the axoneme (Smith and Sale, 1991; Kotani et al., 2007; Wirschell et al., 2007). The I1-dynein complex has been implicated as a target of the regulatory signals that control flagellar motility (Porter et al., 1992; Porter and Sale, 2000; Smith and Yang, 2004; Wirschell et al., 2007). Flagella that are lacking I1 dynein exhibit defective flagellar waveform and phototaxis, indicating that I1 dynein plays a role in these processes (Brokaw and Kamiya, 1987; Brokaw, 1994; King and Dutcher, 1997; Okita et al., 2005).

In Chlamydomonas, four independent loci, when defective, result in a specific failure to assemble the I1-dynein complex in the axoneme (DiBella and King, 2001). Three of these loci encode I1-dynein subunits; ida1, ida2, and ida7 mutants are defective in the $\alpha$-HC, $\beta-\mathrm{HC}$, and IC140, respectively (Myster et al., 1997; Perrone et al., 1998, 2000). Of particular use are novel 
Table 1. I1-dynein components and mutants

\begin{tabular}{|c|c|c|c|c|}
\hline Subunit & Mol. wt. & Gene/mutant & Properties & References \\
\hline $1 \alpha \mathrm{HC}$ & 523 & ida1 (pf9, pf30) & Lacks inner arm I1, slow swimming & $\begin{array}{l}\text { Kamiya et al. (1991) } \\
\text { Myster et al. (1997) } \\
\text { Porter et al. (1992) }\end{array}$ \\
\hline $1 \beta \mathrm{HC}$ & 511 & $i d a 2$ & Lacks inner arm I1, slow swimming & $\begin{array}{l}\text { Kamiya et al. (1991) } \\
\text { Perrone et al. (2000) }\end{array}$ \\
\hline IC140 & 140 & $i d a 7$ & Lacks inner arm I1, slow swimming & $\begin{array}{l}\text { Perrone et al. (1998) } \\
\text { Yang et al. (1998) }\end{array}$ \\
\hline IC138 & 138 & bop5 & $\begin{array}{l}\text { Partial I1 assembly, regulatory phosphoprotein part of } \\
\text { IC138 subcomplex }\end{array}$ & King et al. (1997) \\
\hline & & & & $\begin{array}{l}\text { Hendrickson et al. (2004) } \\
\text { Bower et al. (2009) }\end{array}$ \\
\hline IC97 (IC110) & $90(110)$ & & $\begin{array}{l}\text { Non-WD repeat protein, } \\
\text { homology to Las1/Casc1 proteins, part of IC138 } \\
\text { subcomplex }\end{array}$ & $\begin{array}{l}\text { Porter et al. (1992) } \\
\text { This study }\end{array}$ \\
\hline LC8 & 10 & fla14 & $\begin{array}{l}\text { Required for flagellar assembly, part of I1 dynein, } \\
\text { radial spokes and outer dynein arm }\end{array}$ & $\begin{array}{l}\text { Bower et al. (2009) } \\
\text { Pazour et al. (1998) }\end{array}$ \\
\hline \multirow[t]{3}{*}{ LC7a } & 14 & oda15 & $\begin{array}{l}\text { Required for outer arm assembly, slow swimming, } \\
\text { associates with I1 dynein and may interact with } \\
\text { LC7b }\end{array}$ & $\begin{array}{l}\text { Yang et al. (2001) } \\
\text { Pazour and Witman (2000) }\end{array}$ \\
\hline & & & & DiBella et al. (2004a) \\
\hline & & & & Bowman et al. (1999) \\
\hline $\mathrm{LC7b}$ & 11 & & $\begin{array}{l}\text { LC7/Robl family member, interacts with IC138, } \\
\text { interacts with LC3 and DC } 2 \text { of ODA }\end{array}$ & Dibella et al. (2004a) \\
\hline Tctex1 & 13 & & $\begin{array}{l}\text { Dimeric protein, potential cargo binding activity, also } \\
\text { found in cytoplasmic dynein }\end{array}$ & $\begin{array}{l}\text { Hendrickson et al. (2004) } \\
\text { Harrison et al. (1998) }\end{array}$ \\
\hline Tctex $2 b$ & 13.7 & pf16-D2 & Not required for I1 assembly, stabilizes I1 dynein & DiBella et al. 2004a \\
\hline FAP120 & 42 & & $\begin{array}{l}\text { Not required for I1 dynein assembly, ankryn repeat } \\
\text { protein, part of IC138 subcomplex }\end{array}$ & Ikeda et al. (2009) \\
\hline
\end{tabular}

mutations in I1-dynein subunits that permit assembly of partial I1-dynein complexes (Perrone et al., 1998; Hendrickson et al., 2004; Bower et al., 2009). These novel mutations allow for detailed analysis of I1-dynein subunit interactions and function. For example, in the bypass of paralysis (bop)5-1 mutant, expressing a C-terminal truncation of IC138, I1 dynein assembles but lacks LC7b (Hendrickson et al., 2004) and FAP120 (Ikeda et al., 2008; Bower et al., 2009), indicating that IC138, LC7b, and FAP120 interact. IC138 is a phosphoprotein in I1 dynein and is a key substrate for the regulatory mechanisms that control flagellar motility (reviewed in Porter and Sale, 2000; Wirschell et al., 2007).

To date, all of the known I1-dynein subunits, except IC97, have been cloned and characterized. To better understand I1-dynein function in flagellar motility and how I1 dynein is assembled, we determined the identity of the IC97 subunit. IC97 is a novel IC; it does not encode WD-repeat motifs like other known dynein ICs and is highly conserved, sharing homology with proteins in a number of organisms that assemble motile cilia/flagella, notably, the Las1 protein implicated in pulmonary carcinoma in mice (Zhang et al., 2003). Within the axoneme, IC97 interacts with both $\alpha$ - and $\beta$-tubulin subunits; and within I1 dynein, IC97 interacts with both IC140 and IC138 at the base of the dynein complex. IC97 forms part of a regulatory subcomplex of I1-dynein proteins that includes IC138, LC7b, and FAP120 (Ikeda et al., 2008) that is now referred to as the IC138 subcomplex (Bower et al., 2009).

Analysis of mutants that assemble partial I1-dynein complexes reveal that both IC97 and IC138, although not necessary for I1-dynein assembly, are required for regulation of I1 dynein. One such mutant, a new allele at the LC8 locus, fla14-3, assembles I1-dynein complexes that are devoid of IC97. fla14-3 mutant axonemes show reduced microtubule sliding velocities that are not rescued by kinase inhibitors even though IC138 seems to become dephosphorylated, demonstrating that IC97 plays a critical role in regulation of I1-dynein activity.

\section{MATERIALS AND METHODS}

\section{Strains and Culture Conditions}

Chlamydomonas strains used in this study are summarized in Table 2. Cells were grown in Tris-acetate-phosphate medium or L-medium, with aeration on a 14:10-h light:dark cycle (Harris, 1989; Harris, 2009).

\section{Cloning and Sequencing of IC97 Sequences}

The cloning of IC97 was based on tandem mass spectrometry (MS/MS) identification of peptides derived from band-purified IC97 protein. Gene model C_850038 in the JGI Chlamydomonas genome database version 2.0 (http://shake.jgi-psf.org/chlre2/chlre2.home.html) encodes the IC97 gene (Supplemental Figure S1) and was used to design primers (Integrated DNA Technologies, Coraville, IA) for polymerase chain reaction (PCR) amplification of IC97 cDNA sequences (cDNA library 7 provided by Greg Pazour (University of Massachusetts, Amherst, MA). PCR products were cloned into pGEM-T-Easy (Promega, Madison, WI) or pCR2.1/GW8/TOPO cloning vectors (Invitrogen, Carlsbad, CA) and sequenced to verify intron-exon boundaries (DNA Sequencing Facility, Iowa State University, Ames, IA). The fulllength cDNA is $2.973 \mathrm{~kb}$.

An IC97 cDNA probe containing base pairs 1343-2685 (Supplemental Figure S1B) was used to screen a BAC library (Clemson University Genomics Institute, Clemson, SC) and a 9.791-kb genomic EcoR1-HindIII fragment containing the IC97 gene was identified and subcloned into pBlueScript SK-vector (plasmid IC97-H). IC97 is found in the flagellar proteome as FAP94 (Pazour et al., 2005) and is published under accession FJ156240 and FJ156241 for the gene and cDNA sequences, respectively. 
Table 2. Chlamydomonas strains used in this study

\begin{tabular}{|c|c|c|c|}
\hline Strain & Defect & Motility & References \\
\hline CC124 & & WT & Harris $(1989,2009)$ \\
\hline CC1331 (fla14-3) $)^{\mathrm{a}, \mathrm{b}}$ & Radial spokes, I1 dynein, retrograde IFT & Paralyzed & Yang et al., unpublished \\
\hline CC-4077 (ida7-1::IC140 5A) ${ }^{\mathrm{c}}$ & Truncated IC140 & WT & Perrone et al. (1998) \\
\hline ida7-1::IC140 5A oda9 & $\begin{array}{l}\text { Truncated IC140; lacks outer dynein } \\
\text { arm }\end{array}$ & Slow-jerky swimming & This study \\
\hline CC-4080 (bop5-1) & $\begin{array}{l}\text { Partial I1 dynein assembly; IC138 point } \\
\text { mutant }\end{array}$ & $\begin{array}{l}\text { Slow-smooth } \\
\text { swimming }\end{array}$ & $\begin{array}{l}\text { Dutcher et al. (1988); Hendrickson et al. } \\
\text { (2004) }\end{array}$ \\
\hline bop5-2 & $\begin{array}{l}\text { Partial I1 dynein assembly; null IC138 } \\
\text { allele }\end{array}$ & $\begin{array}{l}\text { Very slow swimming, } \\
\text { spinning cells }\end{array}$ & Bower et al. (2009); Dutcher et al. (1988) \\
\hline CC-2664 (ida1) & Lacks I1 dynein; $1 \alpha \mathrm{HC}$ mutant & $\begin{array}{l}\text { Slow-smooth } \\
\text { swimming }\end{array}$ & $\begin{array}{l}\text { Kamiya et al. (1991); Myster et al. } \\
\text { (1997) }\end{array}$ \\
\hline CC-2666 (ida2) & Lacks I1 dynein; $1 \beta \mathrm{HC}$ mutant & $\begin{array}{l}\text { Slow-smooth } \\
\text { swimming }\end{array}$ & $\begin{array}{l}\text { Kamiya et al. (1991); Perrone et al. } \\
\text { (2000) }\end{array}$ \\
\hline CC-2668 (ida3) & $\begin{array}{l}\text { Lacks I1 dynein; gene product } \\
\text { unknown. }\end{array}$ & $\begin{array}{l}\text { Slow-smooth } \\
\text { swimming }\end{array}$ & Kamiya et al. (1991) \\
\hline CC-2670 (ida4) & Lacks inner arm isoforms a, c, and d & Slow swimming & Kamiya et al. (1991) \\
\hline CC-3921 (ida7) & Lacks I1 dynein; IC140 mutant & $\begin{array}{l}\text { Slow-smooth } \\
\text { swimming }\end{array}$ & $\begin{array}{l}\text { Perrone et al. (1998); Yang and Sale } \\
\quad(1998)\end{array}$ \\
\hline CC-262 (pf17 mt-) & Lacks radial spoke head; RSP1 mutant & Paralyzed & McVittie (1972); Huang et al. (1981) \\
\hline $5 c 12 B$ & HA-tagged $\alpha_{1}$-tubulin & WT & Kozminski et al. (1993) \\
\hline$p f 28 p f 30 \operatorname{ssh} 1^{\mathrm{d}}$ & $\begin{array}{l}\text { Lacks outer dynein arm; Lacks I1 } \\
\text { dynein; suppressor of short mutation }\end{array}$ & Paralyzed & $\begin{array}{l}\text { Ledizet and Piperno (1986); Freshour et } \\
\text { al. (2007) }\end{array}$ \\
\hline
\end{tabular}

a Yang, Yang, Wirschell, and Davis (unpublished) determined that the pf5 mutation in strain CC1331 is an allele at the FLA14 locus (fla114-3) that encodes the LC8 protein. Other strains denoted as pf5 in the Chlamydomonas Stock Center contain a mutation that is tightly linked to the FLA14 locus and thus are not fla14-3/pf5 alleles.

${ }^{\mathrm{b}}$ Assembly defects in fla14-3 include an effect on the retrograde IFT motor as evidenced by assembly of half to full-length flagella; no defects in assembly of the outer dynein arm are observed; I1-dynein assembly defects are restricted to loss of IC97 and FAP120 specifically; and the radial spokes are reduced resulting in the paralyzed flagellar phenotype.

c The ida7-1::IC140 5A strain was first described in Perrone et al. (1998).

d Strain pf28 pf30 ssh1 is a triple mutant lacking both the outer dynein arm and I1 dynein; the ssh1 mutation allows for wild-type length flagella in the double dynein mutant background (LeDizet and Piperno, 1995; Freshour et al., 2006).

\section{Computational Analyses}

Sequence alignments were performed using LaserGene SeqMan (DNAStar, Madison, WI). The LaserGene EditSeq module was used for translations and to estimate the predicted mass of the IC97 protein. Primers were designed using Primer3 (www.genome.wi.mit.edu/coi-bin/primer/primer3) (Rozen and Skaletsky, 2000). The BLAST program (Altschul et al., 1990) was used to search for homologous sequences. The COILS program (www.ch.embnet. org/software/COILS form.html) was used to predict coiled-coil regions in IC97 and its orthologues. ClustalW, version 1.82, was used for alignment and comparison of the murine Las1 protein (AAQ93498.1) and IC97 (http:// www.ebi.ac.uk/Tools/clustalw2/index.html).

\section{Isolation of Axonemes, Dynein Purification, and Biochemical Analyses}

Flagella were isolated as described previously (Witman, 1986) and demembranated using NP-40 (Calbiochem, San Diego, CA). Axonemes were resuspended in HMDEKP $\left(30 \mathrm{mM}\right.$ HEPES, $\mathrm{pH} 7.4,5 \mathrm{mM} \mathrm{MgSO}_{4}, 1 \mathrm{mM}$ dithiothreitol [DTT], $0.5 \mathrm{mM}$ EDTA, $25 \mathrm{mM} \mathrm{KCl}$, and $1 \mathrm{mM}$ phenylmethylsulfonyl fluoride) plus the protease inhibitors aprotinin and leupeptin (Sigma-Aldrich, St. Louis MO). Dyneins were extracted in HMDEKP plus $0.6 \mathrm{M} \mathrm{KCl}$ and fractionated by fast-performance liquid chromatography (FPLC) on a MonoQ column (GE Healthcare, Piscataway, NJ) as described previously (Kagami and Kamiya, 1995).

Chemical cross-linking was carried out using 1-ethyl-3-[3-dimethylaminopropyl] carbodiimide hydrochloride (EDC) by treating microtubule-bound I1-dynein fractions or treating isolated axonemes with EDC for 30-60 min at room temperature, respectively (Benashski and King, 2000; Wirschell et al. 2008). All cross-linking reactions were performed in HMEK buffer $(30 \mathrm{mM}$ HEPES, pH 7.4, $5 \mathrm{mM} \mathrm{MgO}_{4}, 0.5 \mathrm{mM}$ EDTA, and $25 \mathrm{mM} \mathrm{KCl}$ ) supplemented with protease inhibitors. Reactions were neutralized with a 20-fold molar excess of $\beta$-mercaptoethanol. Cross-linked axonemes were collected by centrifugation and resuspended to $2 \mathrm{mg} / \mathrm{ml}$ with sample buffer. SDSPAGE was performed by standard techniques using Precision Plus dualcolor protein standards to estimate relative mobility $\left(M_{\mathrm{r}}\right)$ (Bio-Rad Laboratories, Hercules, CA).
IC138 hyperphosphorylation was determined by comparing untreated and phosphatase-treated axonemes (calf intestinal phosphatase [CIP]) by SDSPAGE. Briefly, axonemes were treated with buffer or CIP for $30 \mathrm{~min}$ at room temperature and then directly fixed for SDS-PAGE analysis.

IC138 phosphorylation status was determined by in vitro phosphorylation of isolated axonemes using radioactive $\left[\gamma_{-}{ }^{32} \mathrm{P}\right] \mathrm{ATP}$ (PerkinElmer Life and Analytical Sciences, Boston, MA) (Yang and Sale, 2000). pf17 and fla14-3 axonemes were resuspended to $5 \mathrm{mg} / \mathrm{ml}$ in CK reaction buffer $(25 \mathrm{mM}$ Tris, $\mathrm{pH} 8.0,0.05 \mathrm{mM}$ EDTA, $0.1 \% \beta$-mercaptoethanol, $3.5 \mathrm{mM}$ magnesium acetate, $0.01 \%$ Brij $35,10 \mathrm{mM} \mathrm{NaCl}$, and $50 \mu \mathrm{M}$ sodium orthovanadate) and incubated at $30^{\circ} \mathrm{C}$ for $30 \mathrm{~min} .\left[\gamma^{32} \mathrm{P}\right] \mathrm{ATP}$ was added to a final concentration of $40 \mu \mathrm{M}$, and axonemes were incubated at $30^{\circ} \mathrm{C}$ for another $5 \mathrm{~min}$. Samples were immediately fixed with sample buffer for analysis on 5\% SDS-PAGE, transferred to nitrocellulose, and subsequently detected by autoradiography. The migration of IC138 was confirmed by Western blot of unlabeled axonemes run on the same gel.

MS/MS analyses of band-purified IC97 and the IC97 cross-linked product were performed at University of Massachusetts Proteomic Mass Spectrometry Laboratory by Dr. John Leszyk. MS/MS spectra were used to search the JGI Chlamydomonas Genome database, version 2.0.

\section{Reconstitution of I1-Dynein Complexes onto Isolated Axonemes}

FPLC-purified I1 dynein and IC97 fractions derived from the double mutant ida7-1::IC140 5A oda9 where dialyzed and then combined with isolated pf 28 pf30 ssh 1 axonemes. The reactions were incubated for $15 \mathrm{~min}$ at room temperature in HMDEKP buffer. Axonemes and supernatant fractions were collected by centrifugation and reconstitution of I1-dynein components analyzed by Western blot.

\section{Antibody Production and Western Blot Analyses}

A restriction fragment containing nucleotides 1737-2492 of the IC97 cDNA (Supplemental Figure S1B) was digested from clone pMW173.1 with BamH1 and EcoR1 and subcloned into the pet28b expression vector (Novagen, San Diego, CA) to create plasmid pMW185.1 (Supplemental 
Figure S1B). The expression construct was transformed into Escherichia coli strain BL21(DE3)pLysS (Stratagene, La Jolla, CA) and expression induced with $1 \mathrm{mM}$ isopropyl $\beta$-D-1-thiogalactopyranoside. The His-tagged fusion protein contains amino acids 443-693 of the IC97 protein sequence. Insoluble inclusion bodies containing the His-tagged IC97 fusion protein were solubilized in $6 \mathrm{M}$ urea in $1 \times$ binding buffer and passed over a nickel column for purification according to the manufacturer's instructions (Novagen). The eluted fusion protein was used as an antigen for production of an IC97specific antiserum (Spring Valley Laboratories, Woodbine, MD). Western blots were probed with the following antibodies: IC97 antiserum (W2-T), 1:10,000; IC138 antiserum, 1:20,000 (Hendrickson et al., 2004); IC140 antiserum, 1:10,000 (Yang and Sale, 1998); R4058 against LC8, 1:1000 (King and Patel-King, 1995); and anti-hemagglutinin (HA) high-affinity rat monoclonal antibody, 1:500 (Roche Diagnostics, Mannheim, Germany). Images were acquired by exposing blots to $\mathrm{x}$-ray film and converted to digital format by scanning and editing in Adobe Photoshop CS2 (Adobe Systems, Mountain View, CA). Figures were prepared using CorelDraw Graphics Suite 13 (Corel, Mountain View, CA).

\section{Immunoprecipitation of IC97-interacting Proteins}

Immunoprecipitation was performed as described previously (King et al., 1991). Briefly, EDC-treated wild-type axonemes were solubilized with SDSsample buffer and diluted 20-fold with Tris-buffered saline (TBS) buffer (10 $\mathrm{mM}$ Tris, $\mathrm{pH} \mathrm{7.5,} \mathrm{and} 150 \mathrm{mM} \mathrm{NaCl}$ ). The diluted axonemes were precleared with protein A beads (Sigma-Aldrich) for 2-3 h, and then incubated with protein A beads bound with the IC97 antiserum. The immune complexes were collected, washed with TBS buffer plus 1\% NP-40 and $0.05 \%$ Tween 20 and fixed with SDS-sample buffer. The immunoprecipitated were separated by SDS-PAGE and analyzed by Western blot and protein stain.

\section{Microtubule Binding Assays and Tubulin Blot Overlays}

Purified tubulin (Cytoskeleton, Denver, CO) was polymerized at $37^{\circ} \mathrm{C}$ in the presence of $10 \mu \mathrm{M}$ Taxol (Cytoskeleton), and microtubules were collected by centrifugation. Taxol-stabilized microtubules were incubated with FPLC-purified I1-dynein fractions containing $10 \mu \mathrm{M}$ Taxol for $30 \mathrm{~min}$ at room temperature and the I1-dynein-bound microtubules and then collected by centrifugation. The I1-dynein-bound microtubule pellets were cross-linked as described above and then fixed for SDS-PAGE. Tubulin blot overlays were performed as described previously (Yanagisawa and Kamiya, 2004).

\section{Microtubule Sliding Assay}

In vitro microtubule sliding assays were performed based on the methods of Okagaki and Kamiya (1986), with modifications (Kagami and Kamiya, 1992; Howard et al., 1994; Habermacher and Sale, 1997). Briefly, axonemes from strains CC1331 (fla14-3), pf17, and CC124 were resuspended in motility buffer (10 mM HEPES, pH 7.4, 5 mM MgSO, 1 mM DTT, 0.5 mM EDTA, 25 mM potassium acetate, and $1 \%$ polyethylene glycol 20,000), loaded into a perfusion chamber, and sliding events were initiated by perfusion of motility buffer containing $1 \mathrm{mM}$ ATP and subtilisin A, type VIII protease (Sigma-Aldrich). Sliding events were observed by darkfield microscopy and recorded by SIT camera and converted to a digital image for analysis by using LabView 7.1 software (National Instruments, Austin, TX). Microtubule displacement was measured manually from tracings calibrated with a micrometer and used to calculate sliding velocities.

\section{RESULTS}

\section{Identification of the IC97 Subunit of I1 Dynein}

To identify the IC97 subunit, I1-dynein, purified by FPLC was resolved on SDS-PAGE, and proteins were stained with Coomassie (data not shown). The band corresponding to the IC97 subunit was excised, digested with trypsin, and peptides were separated by liquid chromatography. MS/MS analyses of the resulting peptides were used to search the Chlamydomonas genome database and identified a candidate gene model (C_850038 in JGI version 2). In total, 17 individual peptides were identified that span the gene model (Supplemental Figure S1A). The gene model prediction is influenced by the presence of gaps in the genomic sequence. As a result, three peptides seem to reside in predicted introns and one peptide resides in the predicted $5^{\prime}$ untranslated region (UTR). Gene model C_850038 (FAP94) was identified in the $\mathrm{KCl}$ fraction of the flagellar proteome (Pazour et al., 2005), a result consistent with a dynein protein.

\section{Cloning IC97 Sequences}

To verify the exact sequence of the protein encoded by gene model C_850038, we designed primers based on predicted exons and the peptides identified by MS/MS. Sequences from a wild-type Chlamydomonas cDNA library were amplified by PCR and sequenced to confirm the complete open reading frame (ORF) plus 412-base pairs of $5^{\prime}$ and 282-base pairs of 3' UTRs. The ORF predicts a 759-amino acid protein with a mass of $81.5 \mathrm{kDa}$ (Supplemental Figure S1A). Using the antisense strand of the cDNA as a probe, we performed a Northern blot on RNA derived from cells either before or during flagellar regeneration. An $\sim 2.8-\mathrm{kb}$ transcript is detected that is up-regulated in response to deflagellation and flagellar regrowth (data not shown), a hallmark of mRNAs encoding flagellar proteins (Silflow et al., 1982).

\section{IC97 Is a Non-WD Repeat IC That Has Orthologues in Ciliated Organisms}

The predicted protein was analyzed by BLAST and found to have homology to several proteins, including a Ciona intestinalis axonemal protein (BAB88834.1) and a murine protein, Las1 (Zhang et al., 2003; Manenti et al., 2004), that is part of the multigenic Pas1 locus associated with an inherited predisposition to pulmonary carcinoma in mice. Alignment of the Chlamydomonas and murine proteins shows the homology spans the entire sequence (Figure 1). Other than a small region in the $\mathrm{N}$ terminus that is predicted to form a coiledcoil, the IC97 protein does not have any notable motifs including WD-repeat domains that are found in other dynein intermediate chains.

\section{IC97 Antiserum Detects the IC97 Component of I1 Dynein}

To determine whether the gene we identified by MS/MS does indeed encode the IC97 subunit of I1 dynein, we made a specific polyclonal immune sera to an epitope-tagged fusion protein containing amino acids 443-693 of the predicted IC97 protein (Supplemental Figure S1B). In Western blots of isolated axonemes, the antibody detects a band having a $M_{\mathrm{r}}$ of $\sim 90,000$ on SDS-PAGE (Figure 2A), well in agreement with the predicted mass of $81.5 \mathrm{kDa}$ (The $M_{\mathrm{r}}$ of 90,000 is estimated from our SDS-PAGE gels. The mass of IC97 has been previously estimated as 97 and $110 \mathrm{kDa}$; Porter et al., 1992; Habermacher and Sale, 1997. This discrepancy is most likely due to differences in the molecular weight standards used). This band is specifically missing in I1-dynein-deficient axonemes (ida1, ida3, and ida7), indicating that the antiserum detects an I1-dynein component. To further verify this, we purified I1 dynein by FPLC fractionation. The antiserum detects the same size band in purified I1-dynein (dynein-f peak) fractions (Figure 2B). These results demonstrate that our antibody specifically detects the IC97 component of I1 dynein.

\section{IC97 Interacts with $\alpha$ - and $\beta$-Tubulin Components}

The IC97 protein sequence does not predict any notable domains or motifs that would lend insight into the function of IC97. Thus, to better understand the role of IC97 in I1 dynein, we took advantage of EDC chemical cross-linking to identify IC97-binding proteins. EDC is a proven reagent for identifying axonemal interactions, particularly for the axonemal dyneins (King et al., 1991; Yang and Sale, 1998; Benashski and King, 2000; DiBella et al., 2004a; Hendrickson et al., 2004). Western blots of EDC-treated axonemes were probed with the IC97 antibody, which detected an EDC cross-linked product, with an $M_{\mathrm{r}}$ of $\sim 140,000$, suggesting 


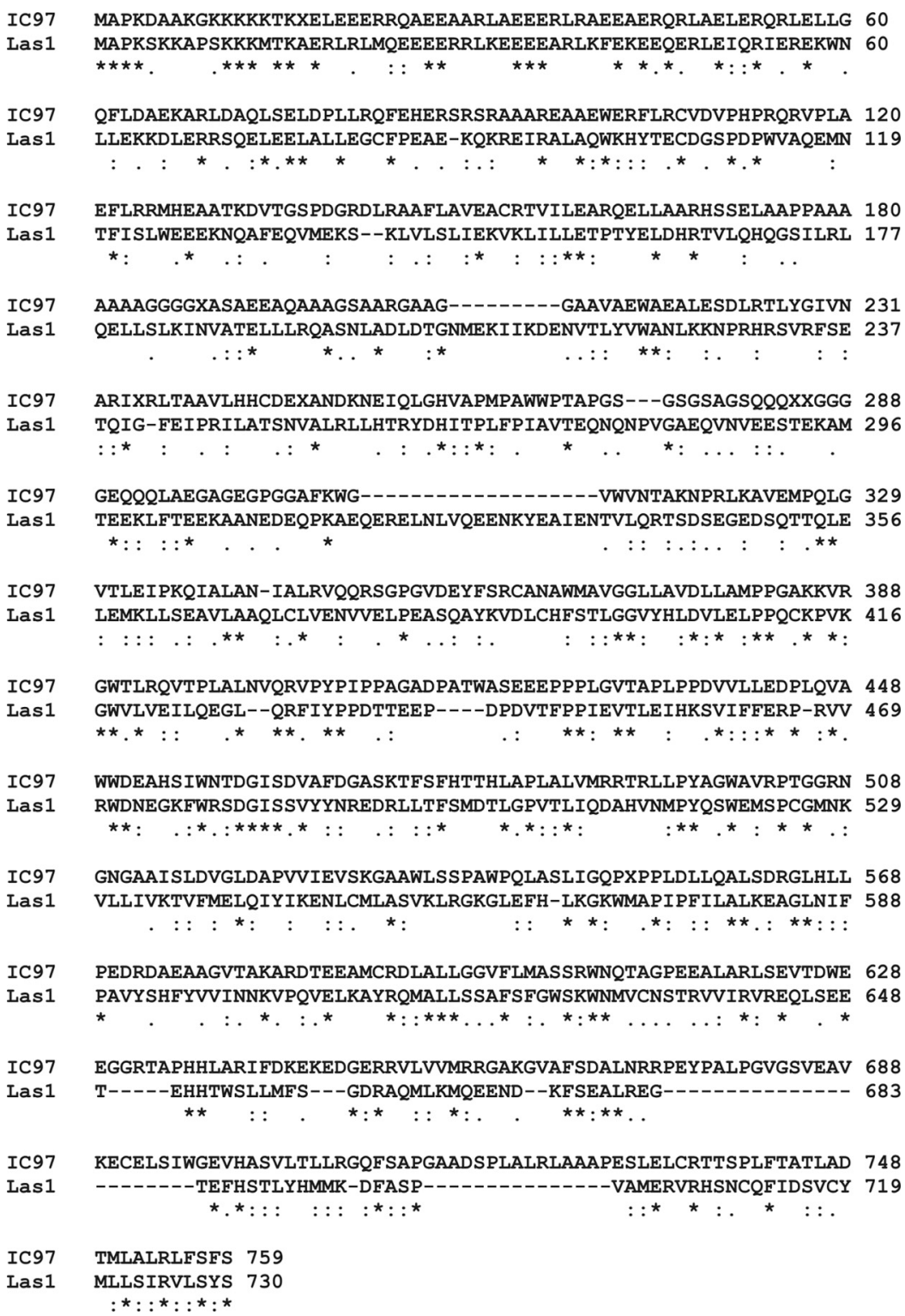

IC97 $\left(M_{\mathrm{r}}\right.$ of $\left.\sim 90,000\right)$ is in direct contact with an axonemal protein with an estimated mass of $50 \mathrm{kDa}$ (Figure 3A).

To determine the identity of the IC97-interacting protein, we used the IC97 antiserum to immunoprecipitate the IC97 cross-linked product in sufficient yield for identification (Figure 3B). MS/MS analysis of the IC97 cross-linked product identified peptides corresponding to both $\alpha$ - and $\beta$-tubulin in addition to IC97. The identification of IC97 peptides demonstrates that the band isolated for MS/MS is the IC97 cross-linked product. The $M_{\mathrm{r}}$ of the cross-linked product is $\sim 140,000$ on SDS-PAGE, suggesting that IC97 does not cross-link to a tubulin dimer, but rather IC97 independently cross-links to $\alpha$ - and $\beta$-tubulin. Hence, the cross-linked product is a mixture of IC97- $\alpha$-tubulin and IC97- $\beta$-tubulin species. In support of this model, the ratio of IC97: $\alpha$-tubulin: $\beta$-tubulin peptides recovered is 1.5:1:1, indicating that both $\alpha$ - and $\beta$-tubulin are present in equivalent amounts compared with a nearly twofold amount of IC97.

To further validate the results obtained by MS/MS, we used several approaches. First, we immunoprecipitated the IC97 cross-linked product (Figure 3C, IC97) from SDS-solu- bilized EDC-treated axonemes containing an HA-tagged $\alpha 1$ tubulin (Kozminski et al., 1993). The IC97 cross-linked product is detected using an antibody to the HA tag, indicating that it contains the epitope-tagged tubulin (Figure 3C, HA). Second, we bound purified I1 dynein to Taxol-stabilized microtubules and then performed EDC cross-linking. The IC97 cross-linked product is formed indicating that IC97 interacts with tubulin components in vitro (Figure 3D). Third, we took advantage of a blot overlay assay that uses biotinylated tubulin as a probe to identify tubulin-interacting proteins (Yanagisawa and Kamiya, 2004). Blot overlays of purified dynein fractions detect a tubulin-interacting band at the expected size for IC97 in purified-I1 dynein (dynein-f peak) fractions (asterisk in Figure 3E).

\section{IC97 Interacts with IC138 and IC140 within I1 Dynein}

To further characterize how IC97 assembles within I1-dynein, we took advantage of unique I1-dynein mutants that assemble partial I1-dynein complexes. Figure 4A shows Western blots of isolated axonemes from three mutant 
Figure 2. Antibodies to C_850038 recognize the IC97 subunit of I1 dynein. (A) The IC97 antibody was used to probe Western blots of axonemes derived from wild-type and several dynein mutants. The antibody recognizes a band, with an $M_{\mathrm{r}}$ of $\sim 90,000$ that is present in wild type (WT) and dynein mutants that are defective in the outer dynein arm (oda2), or inner arm subtypes a, c, and d (ida4). This band is specifically missing in I1-dynein mutants (ida1, ida3, and ida7) that fail to assemble I1 dynein in the axoneme. The lower panel contains the Coomassiestained gel showing protein loads. (B) Western blots of FPLC fractions from oda2 dynein extracts were probed with the IC97 antibody (top). The band recognized by the antibody cofractionates with the I1-dynein complex in the dynein- $f$ peak (detected with antibodies to the IC138 subunit; bottom) confirming that the antibody specifically recognizes the IC97 I1-dynein subunit (Porter et al., 1992; Pazour et al., 1998; Yang and Sale, 1998; Kamiya et al., 1991; King and Dutcher, 1997; Myster et al., 1997; Harrison et al., 1998; Bowman et al., 1999; Pazour and Witman, 2000; Perrone et al., 1998, 2000; DiBella et al., 2004b,c; Hendrickson et al., 2004).

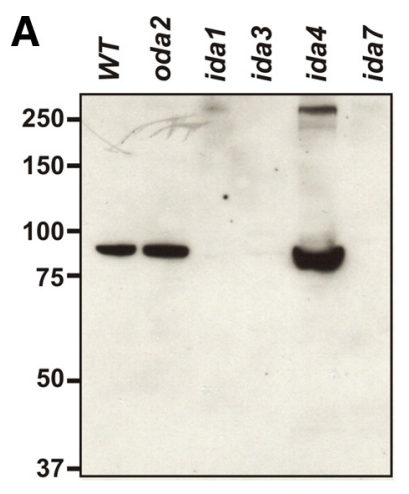

B
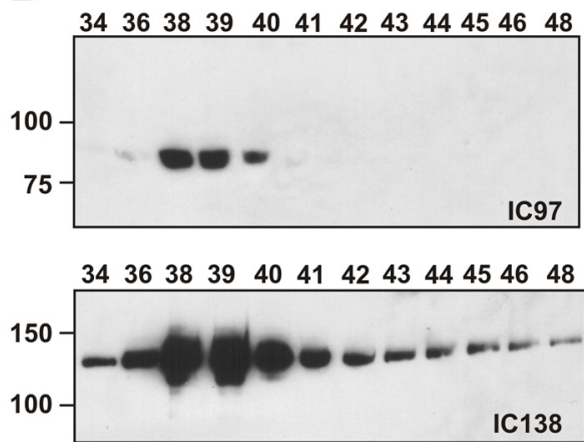

strains: bop5-1-expressing and assembling a truncated IC138 but missing the LC7b and FAP120 subunits of the IC138 subcomplex (Hendrickson et al., 2004; Ikeda et al., 2008), ida7-1::IC140 5A-expressing and assembling a truncated IC140 lacking the $\mathrm{N}$ terminus (see table 1 in Perrone et al., 1998), and bop5-2-an IC138-null allele that assembles I1 dynein lacking IC138, LC7b, and FAP120 (Ikeda et al., 2009; Bower et al., 2009) ida7-1::IC140 5A, but not bop5-2 (Figure 4A). These observations are consistent with other reports, indicating that
IC97 is a component of the IC138 subcomplex and dependent upon IC138 for assembly into I1-dynein (Ikeda et al., 2008; Bower et al., 2009). This interaction is not mediated by LC7b or FAP120 because IC97 assembles in bop5-1, where LC7b and FAP120 are missing (Hendrickson et al., 2004; Ikeda et al., 2008). Thus, we conclude that IC97 is interacting with IC138 directly.

Furthermore, in the bop5-1 mutant, IC97 copurifies with I1-dynein by FPLC fractionation, indicating that it is stably associated with I1 dynein (Hendrickson et al., 2004; our

Figure 3. IC97 interacts with both $\alpha$ - and $\beta$-tubulin. (A) Western blots of wild-type axonemes that were treated with EDC were probed with the IC97 antibody. A prominent cross-linked product of $\sim 140-\mathrm{kDa}$ is formed (arrow; uncross-linked IC97 is marked by the arrowhead). (B) The IC97 antibody was used to immunoprecipitate the cross-linked product (arrow; uncrosslinked IC97 is marked by the arrowhead). The image is a representative silver-stained gel of the immune complexes showing that the IC97 antibody pulls down both uncross-linked IC97 (arrowhead) and the EDC-generated cross-linked product (arrow). The band corresponding to the cross-linked product was excised from an identical SYPRO Ruby-stained gel and components identified by tandem mass spectrometry. The crosslinked product represents a mixture of IC97 crosslinked to a-tubulin and IC97 cross-linked to $\beta$-tubulin. (C) Western blots of the IC97-immune complexes derived from EDC-treated axonemes containing HAtagged $\alpha 1$-tubulin (Kozminski et al., 1993) were probed with the IC97 and HA antibodies. The IC97 antibody detects both uncross-linked (arrowhead) and crosslinked IC97 (arrow). The HA antibody detects only the cross-linked product indicating that it contains IC97 and HA-tagged $\alpha 1$-tubulin. (D) FPLC-purified I1 dynein was bound to Taxol-stabilized microtubules (assembled from purified tubulin) and then EDC crosslinked. The $140-\mathrm{kDa}$ IC97-cross-linked product is formed indicating that IC97 cross-links to tubulin in vitro. (E) Blot overlays using biotinylated tubulin (left) reveal a tubulin-interacting band at the expected size for IC97 in FPLC-purified I1 dynein fractions (asterisk). Also evident is tubulin binding to IC140/IC138 (diamond) of I1 dynein and IC1 (circle) of the outer dynein arm (King et al., 1991). The IC2 component of the outer

A

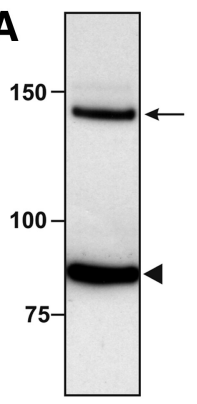

D

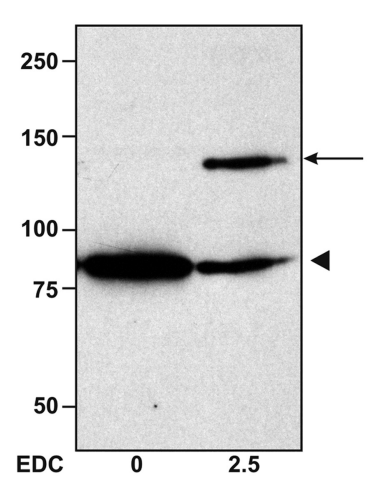

B

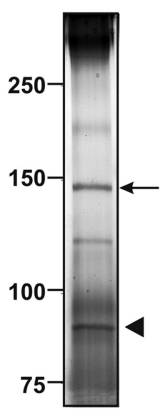

E

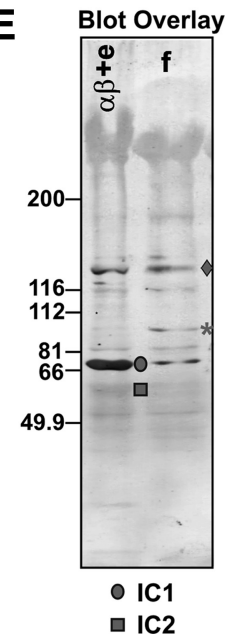

C
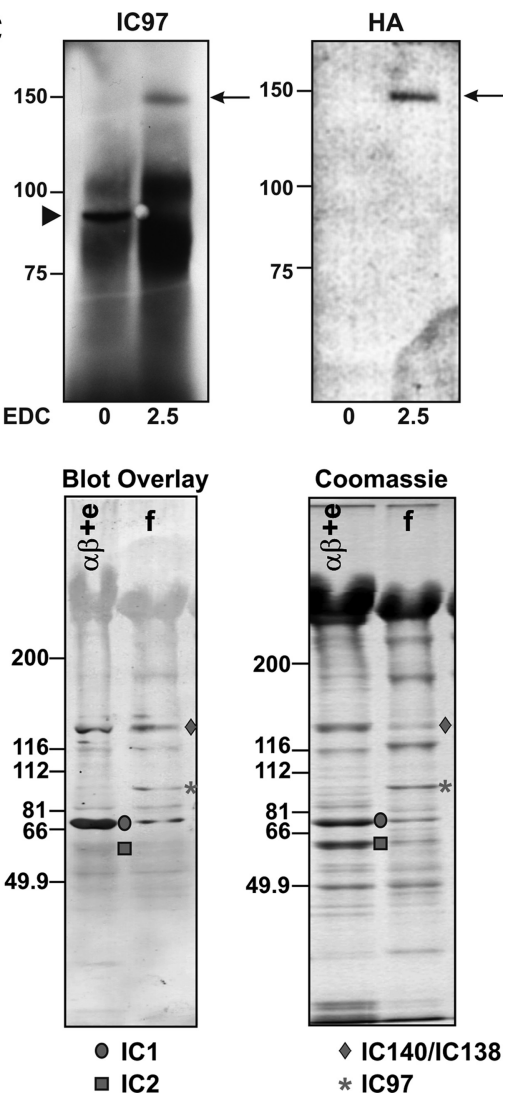

dynein arm is observed in the Coomassie-stained gel (right), but it is not detected in the blot overlay. The left lanes $(\alpha \beta+\mathrm{e})$ are purified outer dynein arm fractions; the right lanes (f) are purified I1-dynein fractions. 


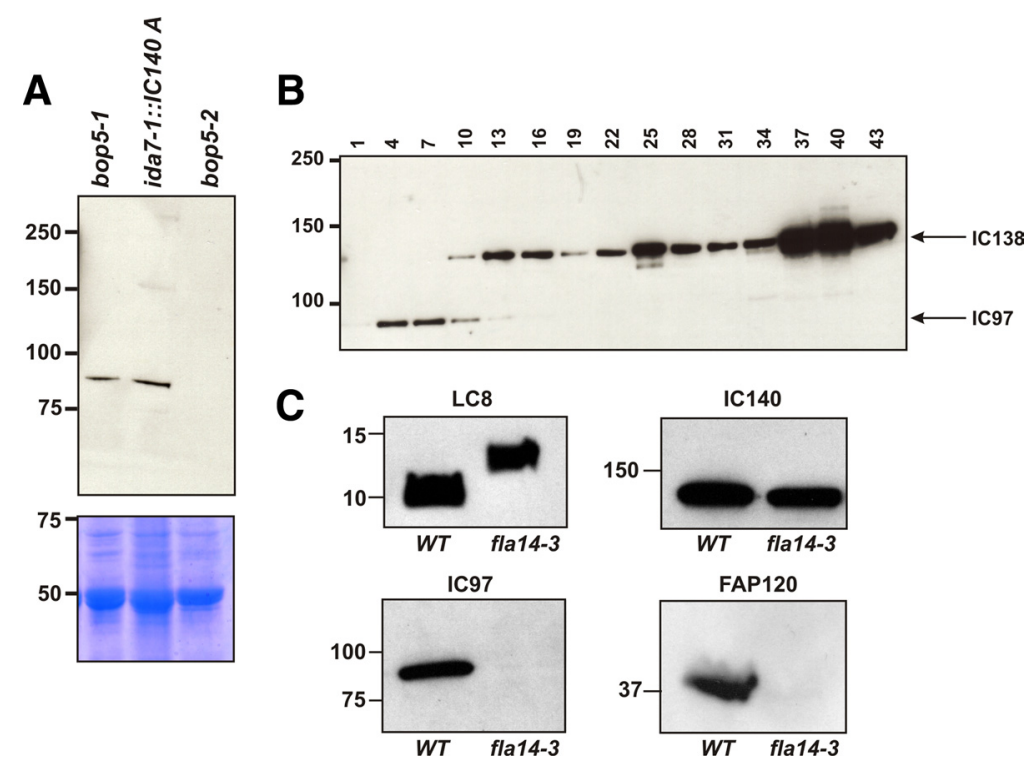

Figure 4. IC97 is not required for I1-dynein assembly or anchoring in the axoneme. (A) Western blots of partial I1-dynein assembly mutants bop5-1, ida7-1::IC140 $5 A$, and bop5-2. IC97 assembles into axonemes of both ida7-1::IC140 5A and bop5-1 but does not localize to the axoneme when IC138, FAP120, and LC7b are missing (bop5-2). Bottom, Coomassie-stained gel of the same samples. (B) FPLC fractions of dynein extracts from a double mutant ida7-1::IC140 5A oda9 demonstrate that IC97, while assembled in the axoneme, does not cofractionate with I1 dynein, but rather is detected in earlier fractions. (C) Western blots of axonemes from a new LC8 mutant, fla14-3 that expresses a larger LC8 protein (top, left; Yang, Yang, Wirschell, and Davis, unpublished data), demonstrates that IC97 and FAP120 fail to assemble in the axoneme (bottom). The rest of the I1dynein complex seems to assemble in the absence of IC97/FAP120 (represented by IC140; top, right). unpublished data). In contrast, although IC97 assembles in ida7-1::IC140 5A, it does not cofractionate with I1 dynein (derived from the ida7-1::IC140 5A oda9 double mutant and represented by IC138 in Figure 4B), indicating that IC97 requires the $\mathrm{N}$ terminus of IC140 for stable association with the I1-dynein complex and suggesting that IC97 and IC140 also interact. Together, these results suggest that IC97 interacts with both IC138 and IC140 within I1-dynein, further defining interactions of I1-dynein subunits in the higher order dynein motor complex.

\section{IC97 Is Not Required for I1-Dynein Assembly or for Anchoring in the Axoneme}

The results from the bop5-2 mutant demonstrate that IC97 is not required for I1-dynein assembly or anchoring in the axoneme (Bower et al., 2009). To verify this, we tested whether I1-dynein complexes that lack IC97 (derived by salt extraction from strain ida7-1::IC140 5A oda9) can rebind I1-dynein-deficient axonemes in an in vitro reconstitution assay. Supplemental Figure S2 shows that I1-dynein complexes can rebind to I1-deficient axonemes in the absence of IC97, indicating that IC97 is not required for I1-dynein anchoring to the axoneme.

Furthermore, analysis of a newly identified LC8 mutation fla14-3 (identified as the defective gene in the motility mutant $p f 5$ ), demonstrates that I1 dynein (identified by IC140) assembles without IC97 and FAP120 (Figure 4C). The fla14-3 mutant expresses a larger LC8 protein due to a read-through mutation in the LC8 stop codon (Figure 4C; Yang, Yang, Wirschell, and Davis, unpublished data). LC8 is a component of several flagellar complexes, including the retrograde intraflagellar transport (IFT) motor, the outer dynein arm, I1 dynein, and the radial spokes. This particular fla14 allele affects assembly of the I1-dynein components listed above and the radial spokes but does not affect assembly of the outer dynein arm. There also may be an effect on the retrograde IFT motor as evidenced by assembly of half- to fulllength flagella. A detailed characterization of the assembly defects in fla14-3 is described in Yang, Yang, Wirschell, and Davis (unpublished data).

\section{IC97 Is Required for Control of Microtubule Sliding}

Because IC97 is not required for assembly of I1 dynein, we predicted that IC97 may function with IC138 in the regula- tion of I1-dynein activity. Based on analysis of bop5-1 axonemes, FAP120 and LC7b do not seem to function in the regulatory pathway that controls I1 dynein (Hendrickson et al., 2004; Ikeda et al., 2008). Therefore, we reasoned that we could use the fla14-3 mutant to test the role of IC97 in regulation of I1-dynein activity using the microtubule sliding assay. We did not need to combine the fla14-3 mutation with a mutation such as pf17 that disrupts radial spoke assembly because fla14-3 itself is inherently defective in assembly of the radial spokes (Huang et al., 1981; Yang, Yang, Wirschell, and Davis, unpublished data). Defects in radial spoke assembly lead to disruption of the signaling pathway that regulates I1 dynein, resulting in hyperphosphorylated IC138 and inhibition of microtubule sliding. Given the radial spoke defect in fla14-3, we predict that IC138 is hyperphosphorylated in fla14-3 axonemes. As expected, IC138 is hyperphosphorylated, similar to the radial spoke mutant $p f 17$, indicating that there is a defect in the regulatory pathway in fla14-3 axonemes, a result that is consistent with the radial spoke defect present in this mutant (Figure 5A; compare CIP-treated to untreated axonemes; also see Hendrickson et al., 2004).

To test whether IC97 plays a regulatory role, we used the in vitro microtubule sliding assay to compare I1-dynein function in axonemes that contain IC97 (wild-type and pf17) with fla14-3 axonemes that lack IC97. Consistent with previous reports, relative to wild-type axonemes, microtubule sliding is greatly reduced in pf17 axonemes (Figure 5B). Like other radial spoke mutants, microtubule sliding velocities in fla14-3 axonemes are greatly reduced (Figure 5B). However, unlike other radial spoke mutants, the slow microtubule sliding in fla14-3 axonemes is not rescued by kinase inhibitors (Figure 5B). These results are consistent with the hypothesis that IC97 plays a critical role, along with IC138, in the regulation of I1-dynein activity.

The central pair/radial spoke signaling mechanism has been shown to impinge upon the IC138 subunit of I1 dynein and rescue of microtubule sliding velocities correlates with dephosphorylation of IC138 (Habermacher and Sale, 1997). To further understand the failure to rescue microtubule sliding velocities with kinase inhibitors, we used an in vitro phosphorylation assay to test whether there is a defect in dephosphorylation of IC138 in fla14-3 axonemes. Isolated 
Figure 5. IC97 is required for regulation of microtubule sliding. (A) Western blots of isolated axonemes from $p f 17$ and fla14-3 were probed with an antibody to the IC138 I1dynein subunit. Axonemes were untreated or treated with CIP. IC138 is extensively phosphorylated (hyperphosphorylated) in radial spoke mutants such as pf17 and in the fla14-3 mutant (compare the untreated vs. treated bands; Hendrickson et al., 2004). (B) Microtubule sliding velocities were measured in wild-type, pf17, and fla14-3 axonemes (bars indicate means + SD). Sliding rates were reduced in fla14-3 axonemes relative to wild type-a result consistent with other radial spoke mutant axonemes (pf17). In contrast to pf17 axonemes, the sliding rates of fla14-3 axonemes do not increase upon addition of the kinase inhibitors protein kinase inhibitor (PKI) or DRB indicating that IC97 is required for PKI/DRBmediated rescue of microtubule sliding. (C) In vitro phosphorylation of $p f 17$ or fla14-3 axonemes by using [ $\left.\gamma^{-32} \mathrm{P}\right] \mathrm{ATP}$ was performed in the presence or absence of CK1-specific inhibitors. In pf17 and fla14-3 axonemes, when axonemes are pretreated with kinase inhibitors (CKI-7 or DRB), radioactive phosphate incorporation into IC138 is reduced, indicating that IC138 is largely dephosphorylated.
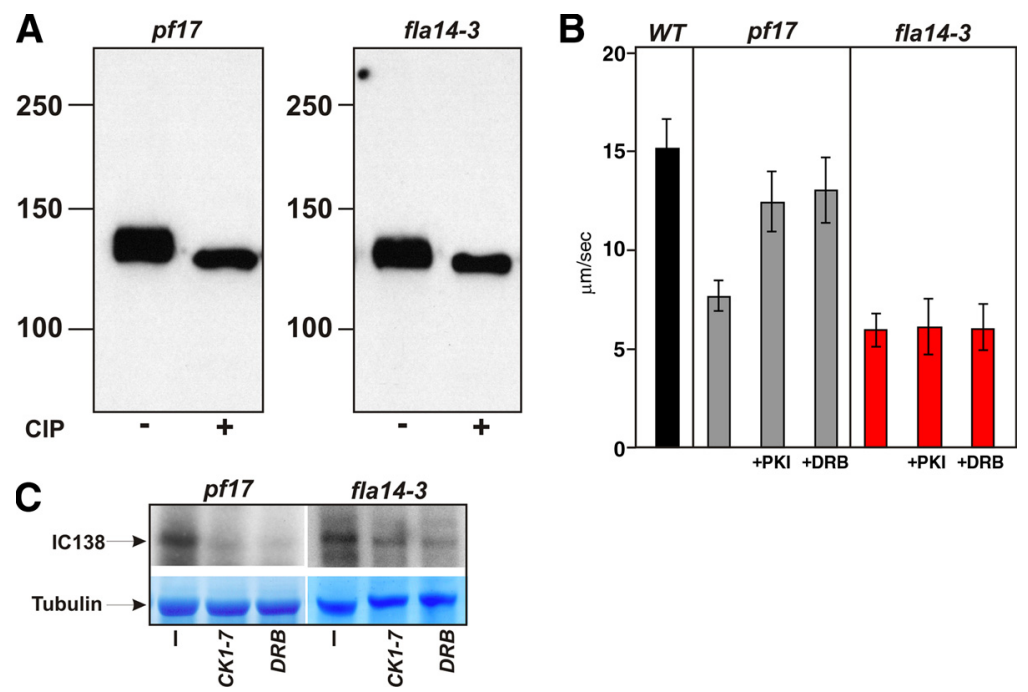

axonemes from $p f 17$ and fla14-3 were incubated with radioactive $\left[\gamma^{-32} \mathrm{P}\right] \mathrm{ATP}$ after treatment with the protein kinase inhibitors CKI-7 or 5,6-dichloro-1- $\beta$-D-ribofuranosylbenzimidazole (DRB) (shown to block IC138 phosphorylation as well as rescue microtubule sliding in isolated axonemes; Yang and Sale, 2000). Consistent with previous reports (Yang and Sale, 2000), incorporation of radioactive phosphate is reduced when pf17 axonemes are treated with the kinase inhibitors (Figure 5B, pf17, bottom). In fla14-3 axonemes, kinase inhibitor treatment also reduces radioactive phosphate incorporation (Figure 5B, fla14-3, bottom). Although this assay does not detect dephosphorylation at specific residues (see Discussion), the reduction of phosphate incorporation indicates that IC138 is dephosphorylated and that the kinases and phosphatases that regulate IC138 are intact. Thus, although IC138 phosphorylation in axonemes from fla14-3 is inhibited with CKI-7 or DRB, microtubule sliding was not restored to wild-type velocity, further indicating an essential role for IC97 in regulation of I1 dynein.

\section{DISCUSSION}

Here, we describe the IC97 subunit of the conserved I1 dynein motor. IC97 interacts directly with tubulin, and along with IC138, plays a role in regulation of I1 dynein and control of microtubule sliding.

\section{IC97 Interacts with Tubulin Subunits in the Axoneme}

Based on multiple lines of evidence, we determined that IC97 interacts with both $\alpha$ - and $\beta$-tubulin subunits (Figures 3 and $6 \mathrm{~A}$ and Supplemental Figure S2). Our data suggest that IC97 is in direct contact with the A-tubule of the outer doublet, near the I1-dynein docking site. This is consistent with a close association of the I1-dynein IC/LC domain with the wall of the A-tubule (Nicastro et al., 2006; Bui et al., 2008). Given that IC97 is not required for I1-dynein assembly, an IC97-tubulin interaction cannot explain the precise localization of I1 dynein within the $96-\mathrm{nm}$ repeat. The specific localization of I1 dynein in the axoneme may still require additional factors (King and Kamiya, 2009).

The precise function of the IC97-tubulin interaction is unclear. One possibility is that it is part of a mechanism that detects curvature of the axoneme for control of dynein activity and axonemal bending. Experimental and theoretical evidence indicate that mechanical feedback from bending of the axoneme is involved in regulation of dynein activity (Hayashibe et al., 1997; Brokaw, 2002; Lindemann, 2004; Morita and Shingyoji, 2004; Brokaw, 2008; Hayashi and Shingyoji, 2008). It is possible that these mechanically based control mechanisms involve multiple interactions of the dynein motors with the axoneme that include direct interactions with tubulin. Of particular interest is whether these tubulin interactions with dynein intermediate chains are altered during axonemal bending.

\section{IC97 Interactions with I1-Dynein Subunits}

In Figure 6A, we propose a model for how IC97 interacts with the axoneme and I1-dynein components. Shown in red are interactions between IC97-tubulin, IC97-IC140, and the IC97-IC138 subcomplex, including FAP120.

Based on the analysis of the bop5-2 mutant (Bower et al., 2009), we conclude that IC97 assembles into I1 dynein in an IC138-dependent manner, suggesting that these two I1-dynein subunits interact. This interaction is not mediated by the $\mathrm{C}$ terminus of IC138, LC7b, or FAP120 because IC97 is present in bop5-1, where these proteins are missing (Figure 4C) (Hendrickson et al., 2004; Ikeda et al., 2009; Bower et al., 2009). This result suggests that IC97 and IC138 interact directly.

The IC97-IC140 interaction is supported by analysis of the ida7-1::IC140 5A strain (Perrone et al., 1998). Although an intact I1 dynein assembles in this mutant, IC97 is specifically lost upon extraction of I1 dynein from the axoneme (Figure 4B), indicating that IC97 requires the $\mathrm{N}$ terminus of IC140 for a stable association with I1 dynein in vitro. No other I1dynein subunit seems to dissociate in the ida7-1::IC140 5A mutant, suggesting that the IC97-IC140 interaction is also direct.

The model also depicts a possible interaction between IC97 and LC8. Analysis of the fla14-3 mutant indicates that assembly of IC97 and FAP120 are specifically disrupted. However, we predict that the loss of IC97/FAP120 from I1 dynein in fla14-3 is indirect (see below).

\section{IC97 Is Required for I1-Dynein-mediated Control of Microtubule Sliding In Vitro}

I1 dynein is an essential part of a regulatory pathway that controls microtubule sliding and regulates axonemal bend- 
A

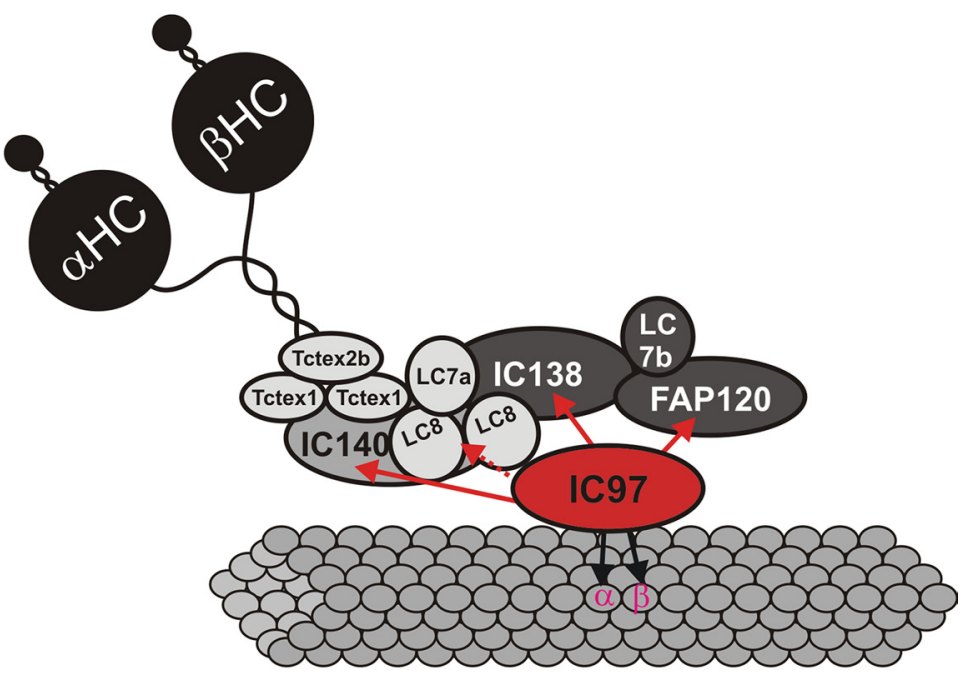

B
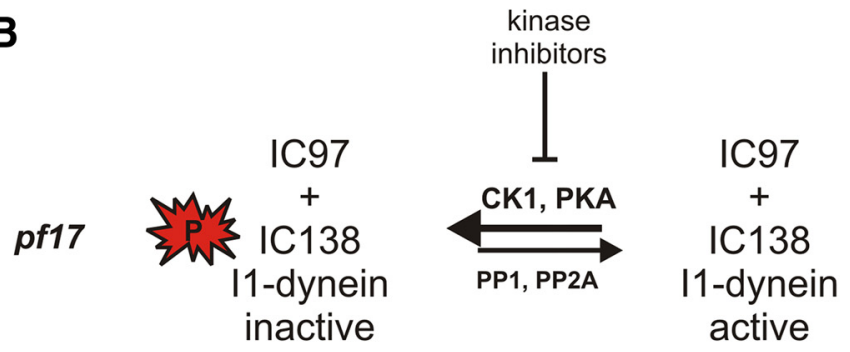

fla14-3

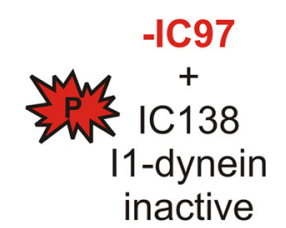

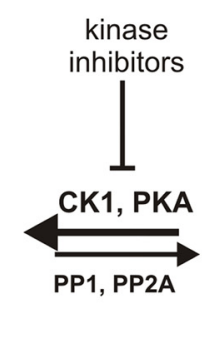

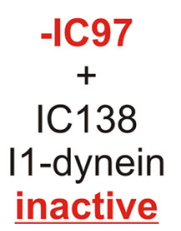

Figure 6. Models for I1-dynein structural interactions and for control of I1-dynein activity. (A) The I1-dynein interaction map showing the IC97 interactions determined in this study. IC97 interacts with IC140 based on analysis of the ida7-1::IC140 5A mutant; IC97 interacts directly with IC138 based on analysis of the bop5-2 mutant; biochemical data indicate a direct interaction between IC97 and $\alpha$ - and $\beta$-tubulin; and IC97 may interact with the LC8 dimer (dashed line) based on our analysis of the fla14-3 mutant, although we hypothesize that IC97 does not directly interact with LC8. In addition, FAP120 may interact with IC97 and the C terminus of IC138 (based on the bop5-1 and fla14-3 mutants). Interactions involving the $\mathrm{LC}$ subunits have not been fully determined, other than the LC7b-IC138 interaction (Dibella et al., 2004a; Hendrickson et al., 2004). (B) A model for regulation of I1-dynein activity showing the requirement of IC97 for I1-dynein activity is shown. In the presence of IC97, such as in pf17 axonemes, I1dynein can be dephosphorylated (extrinsically with kinase inhibitors) and subsequently activated. However in the absence of IC97 (such as in fla14-3), I1 dynein remains inactive even though IC138 dephosphorylation occurs. ing. Figure $6 \mathrm{~B}$ is founded in part on analysis of microtubule sliding in axonemes isolated from paralyzed flagellar mutants defective in assembly of the radial spokes or central pair structures (reviewed in Porter and Sale 2000; Smith and Yang 2004; Wirschell et al., 2007).

Here, we provide evidence that assembly of IC97 is necessary for regulation of I1 dynein and control of microtubule sliding. fla14-3 axonemes assemble an intact I1-dynein that appears to lack only the IC97 and FAP120 subunits (Figure 4C). This mutant allele of LC8 manifests assembly defects in I1 as well as the radial spokes (Huang et al., 1981; Yang, Yang, Wirschell, and Davis, unpublished data). The defect in radial spoke assembly intrinsic to this mutant allele allowed us to use the microtubule sliding assay to directly test the effects of the loss of IC97 on the regulatory pathway that controls I1 dynein. Similar to radial spoke mutants like pf17; IC138 is hyperphosphorylated in fla14-3 (Figure 5A). Furthermore, despite inhibition of IC138 phosphorylation, fla14-3 axonemes do not increase microtubule sliding rates upon treatment with kinase inhibitors, indicating that IC97 is required, along with IC138, for control of I1 dynein. Evidently, dephosphorylation of IC138 is not sufficient for con- trol of microtubule sliding; the assembly of IC97 also is required (Figure 6B).

We cannot rule out the possibility that the microtubule sliding defect in fla14-3 is a result of the mutation in LC8 and a novel defect in radial spoke assembly that allows fla14-3 to behave differently than other radial spoke mutants. However, we propose that the failure to rescue microtubule sliding velocities in fla14-3 is due to the specific loss of IC97 for the following reasons. 1) Recent models propose that the LC8 dimer functions in a structural capacity; establishing and driving the formation of large macromolecular complexes like the dynein motors (Williams et al., 2007; Barbar, 2008; King, 2008). For example, the IC of cytoplasmic dynein is partially disordered and gains structure upon binding to LC8 (Nyarko et al., 2004). Thus, loss of IC97/FAP120 from fla14-3 I1-dynein may be the result of a defective I1-dynein structure that is not competent to recruit these subunits. Such a model would indicate that IC97/FAP120 and LC8 do not interact directly. 2) More importantly, IC97 requires IC138 for assembly into I1 dynein and together they are localized within a subcomplex at the base of I1-dynein (Bower et al., 2009). IC97 can assemble in the absence of LC7b and FAP120 
(bop5-1; Hendrickson et al., 2004; Ikeda et al., 2008), thus it is likely that IC97 is interacting directly with IC138. Because IC97 is intimately associated with IC138, we propose that the failure in regulation of microtubule sliding in fla14-3 is a direct result of the loss of IC97.

The mechanism of how IC97 is contributing to control of I1-dynein activity is unclear. IC138 is hyperphosphorylated in fla14-3, indicating that the phosphoregulatory pathway is disrupted. Furthermore, in vitro phosphorylation assays reveal that IC138 is dephosphorylated in response to kinase inhibitors in fla14-3 axonemes indicating that IC97 functions with IC138 in regulation of I1 dynein. Sakakibara et al. (2006) have demonstrated that a conformational change occurs in I1 dynein upon phosphorylation. We postulate that this alteration in structure requires the assembly of both IC138 and IC97. Regardless of the mechanism, our results indicate that IC97 is a critical regulatory protein that functions in control of microtubule sliding and I1-dynein activity.

\section{IC97 Is Related to Proteins Implicated in Pulmonary Carcinoma}

IC97 has orthologues in many species that contain motile cilia and flagella. Of interest is the observed homology between IC97 and Las1-a protein implicated as a lung tumor susceptibility gene (Zhang et al., 2003). Las1 is highly expressed in lung and testis - tissues that contain motile cilia and in the kidney-a tissue containing immotile, primary cilia (Zhang et al., 2003). Moreover, in dividing cells, Las1 is expressed in G2 and its degradation during mitosis is required for cell cycle progression (Liu et al., 2007). The finding that Las1 is a microtubule-binding protein (Liu et al., 2007) is consistent with the IC97-tubulin interaction described here, suggesting that an interaction with tubulin may be a conserved feature of IC97/Las1 function. The significance of the homology between Chlamydomonas IC97 and the Las1 protein involved in lung tumorigenesis is unclear, but raises the questions of whether Las1 localizes to motile cilia, as well as primary cilia, and whether Las1 plays functional roles both in cilia and outside of the axoneme.

\section{ACKNOWLEDGMENTS}

We thank Jacque Hudak for generating the ida7-1::IC140 5A oda9 double mutant strain; and Cheryl Jones for technical expertise in cloning the IC97 genomic sequences. We also thank Avanti Gokhale and Candice Elam for helpful discussions. This study was supported by National Institutes of Health grants GM-051173 (to W.S.S.), GM-55667 (M.E.P.), GM-30626 (to G.B.W.), and GM-068101 (to P. Y.); National Institutes of Health National Research Service Award postdoctoral fellowship GM-075446 (to M. W.); and a grant from the Ministry of Education, Culture, Sports, Science and Technology (to R. K.).

\section{REFERENCES}

Altschul, S. F., Gish, W., Miller, W., Myers, E. W., and Lipman, D. J. (1990). Basic local alignment search tool. J. Mol. Biol. 215, 403-410.

Barbar, E. (2008). Dynein light chain LC8 is a dimerization hub essential in diverse protein networks. Biochemistry 47, 503-508.

Benashski, S. E., and King, S. M. (2000). Investigation of protein-protein interactions within flagellar dynein using homobifunctional and zero-length crosslinking reagents. Methods 22, 365-371.

Bower, R., VanderWaal, K., O’Toole, E., Fox, L., Perrone, C. A., Mueller, J., Wirschell, M., Kamiya, R., Sale, W. S., and Porter, M. E. (2009). IC138 defines a sub-domain at the base of the I1 dynein that regulates microtubule sliding and flagellar motility. Mol. Biol. Cell 20, 3055-3063.

Bowman, A. B., Patel-King, R. S., Benashski, S. E., McCaffery, J. M., Goldstein, L.S.B., and King, S. M. (1999). Drosophila roadblock and Chlamydomonas LC 7 , a conserved family of dynein-associated proteins involved in axonal transport, flagellar motility, and mitosis. J. Cell Biol. 146, 165-180.
Brokaw, C. J. (1994). Control of flagellar bending: a new agenda based on dynein diversity. Cell Motil. Cytoskeleton 28, 199-204.

Brokaw, C. J. (2002). Computer simulation of flagellar movement VIII: coordination of dynein by local curvature control can generate helical bending waves. Cell Motil. Cytoskeleton 53, 103-124.

Brokaw, C. J. (2008). Thinking about flagellar oscillation. Cell Motil. Cytoskeleton Epub ahead of print.

Brokaw, C. J., and Kamiya, R. (1987). Bending patterns of Chlamydomonas flagella: IV. Mutants with defects in inner and outer dynein arms indicate differences in dynein arm function. Cell Motil. Cytoskeleton 8, 68-75.

Bui, K. H., Sakakibara, H., Movassagh, T., Oiwa, K., and Ishikawa, T. (2008). Molecular architecture of inner dynein arms in situ in Chlamydomonas reinhardtii flagella. J. Cell Biol. 5, 923-932.

Burgess, S. A, Carter, D. A, Dover, S. D, and Woolley, D. M. (1991). The inner dynein arm complex: compatible images from freeze-etch and thin section methods of microscopy. J. Cell Sci. 100, 319-328.

DiBella, L. M., and King, S. M. (2001). Dynein motors of the Chlamydomonas flagellum. Int. Rev. Cytol. 210, 227-268.

DiBella, L. M., Sakato, M., Patel-King, R. S., Pazour, G. J., and King, S. M. (2004a). The LC7 light chains of Chlamydomonas flagellar dyneins interact with components required for both motor assembly and regulation. Mol. Biol. Cell 15, 4633-4646.

DiBella, L. M., Smith, E. F., Patel-King, R. S., Wakabayashi, K., and King, S. M. (2004b). A novel Tctex2-related light chain is required for stability of inner dynein arm I1 and motor function in the Chlamydomonas flagellum. J. Biol. Chem. 279, 21666-21676.

Dutcher, S. K., Gibbons, W., and Inwood, W. B. (1988). A genetic analysis of suppressors of the PF10 mutation in Chlamydomonas reinhardtii. Genetics 120, 965-976.

Freshour, J., Yokoyama, R., and Mitchell, D. R. (2006). Chlamydomonas flagellar outer row dynein assembly protein Oda7 interacts with both outer row and I1 inner row dyneins. J. Biol. Chem. 282, 5404-5412.

Goodenough, U. W., and Heuser, J. E. (1985). Substructure of inner dynein arms, radial spokes, and the central pair/projection complex of cilia and flagella. J. Cell Biol. 100, 2008-2018.

Habermacher, G., and Sale, W. S. (1997). Regulation of flagellar dynein by phosphorylation of a 138-kD inner arm dynein intermediate chain. J. Cell Biol. 136, 167-176.

Harris, E. H. (1989). The Chlamydomonas Sourcebook: A Comprehensive Guide to Biology and Laboratory Use, San Diego, CA: Academic Press.

Harris, E. H. (2009). The Chlamydomonas Sourcebook: Introduction to Chlamydomonas and Its Laboratory Use. Oxford, NY: Academic Press.

Harrison, A., Olds-Clarke, P., and King, S. M. (1998). Identification of the complex-encoded cytoplasmic dynein light chain tctex 1 in inner arm I1 supports the involvement of flagellar dyneins in meiotic drive. J. Cell Biol. 140, 1137-1147.

Hayashi, S., and Shingyoji, C. (2008). Mechanism of flagellar oscillationbending-induced switching of dynein activity in elastase-treated axonemes of sea urchin sperm. J. Cell Sci. 121, 2833-2843.

Hayashibe, K., Shingyoji, C., and Kamiya, R. (1997). Induction of temporary beating in paralyzed flagella of Chlamydomonas mutants by application of external force. Cell Motil. Cytoskeleton 37, 232-239.

Hendrickson, T. W., Perrone, C. A., Griffin, P., Wuichet, K., Mueller, J., Yang, P., Porter, M. E., and Sale, W. S. (2004). IC138 is a WD-repeat dynein intermediate chain required for light chain assembly and regulation of flagellar bending. Mol. Biol. Cell 12, 5431-5442.

Howard, D. R., Habermacher, G., Glass, D. B., Smith, E. F., and Sale, W. S (1994). Regulation of Chlamydomonas flagellar dynein by an axonemal protein kinase. J. Cell Biol. 127, 1683-1692.

Huang, B., Piperno, G., Ramanis, Z., and Luck, D. J. (1981). Radial spokes of Chlamydomonas flagella: genetic analysis of assembly and function. J. Cell Biol. $88,80-88$.

Ikeda, K, Yamamoto, R., Wirschell, M., Yagi, T., Bower, R., Porter, M. E., Sale, W. S., and Kamiya, R. (2008). A novel ankyrin-repeat protein interacts with the regulatory proteins of inner arm dynein $\mathrm{f}$ (I1) of Chlamydomonas reinhardtii. Cell Motil. Cytoskeleton Epub ahead of print.

Kagami, O., and Kamiya, R. (1992). Translocation and rotation of microtubules caused by multiple species of Chlamydomonas inner-arm dynein. J. Cell Sci. 103, 653-664.

Kagami, O., and Kamiya, R. (1995). Separation of dynein species by highpressure liquid chromatography. Methods Cell Biol. 47, 487-489. 
Kamiya, R. (2002). Functional diversity of axonemal dyneins as studied in Chlamydomonas mutants. Int. Rev. Cytol. 219, 115-155.

Kamiya, R., Kurimoto, E., and Muto, E. (1991). Two types of Chlamydomonas flagellar mutants missing different components of inner-arm dynein. J. Cell Biol. 112, 441-447.

King, S. J., and Dutcher, S. K. (1997). Phosphoregulation of an inner dynein arm complex in Chlamydomonas reinhardtii is altered in phototactic mutant strains. J. Cell Biol. 136, 177-191.

King, S. M. (2008). Dynein-independent functions of DYNLL1/LC 8, redox state sensing and transcriptional control. Sci. Signal 1, pe51.

King, S. M., and Kamiya, R. (2009). Axonemal Dyneins: Assembly, Structure, and Force Generation. In: The Chlamydomonas Sourcebook: Cell Motility and Behavior, vol. 3, ed. G. B. Witman, Oxford, NY: Academic Press, 131-208.

King, S. M., and Patel-King, R. S. (1995). The M. (r) = 8,000 and 11,000 outer arm dynein light chains from Chlamydomonas flagella have cytoplasmic homologues. J. Biol. Chem. 270, 11445-11452.

King, S. M., Wilkerson, C. G., and Witman, G. B. (1991). The Mr 78,000 intermediate chain of Chlamydomonas outer arm dynein interacts with alphatubulin in situ. J. Biol. Chem. 266, 8401-8407.

Kotani, N., Sakakibara, H., Burgess, S. A., Kojima, H., and Oiwa, K. (2007). Mechanical properties of inner-arm dynein-f (dynein I1) studied with in vitro motility assays. Biophys. J. 93, 886-894.

Kozminski, K. G., Diener, D. R., and Rosenbaum, J. L. (1993). High level expression of nonacetylatable alpha-tubulin in Chlamydomonas reinhardtii. Cell Motil. Cytoskeleton 25, 158-170.

LeDizet, M., and Piperno, G. (1995). The light chain p28 associates with a subset of inner dynein arm heavy chains in Chlamydomonas axonemes. Mol. Biol. Cell 6, 697-711.

Lindemann, C. B. (2004). Testing the geometric clutch hypothesis. Biol. Cell $96,681-690$.

Liu, Y., Vikis, H. G., Yi, Y., Futamura, M., Wang, Y., and You, M. (2007). Degradation of lung adenoma susceptibility 1, a major candidate mouse lung tumor modifier, is required for cell cycle progression. Cancer Res. 67, 1020710213

Manenti, G., Galbiati, F., Gianni-Barrera, R., Pettinicchio, A., Acevedo, A., and Dragani, T. A. (2004). Haplotype sharing suggests that a genomic segment containing six genes accounts for the pulmonary adenoma susceptibility 1 (Pas1) locus activity in mice. Oncogene 23, 4495-4504.

Mastronarde, D. N., O'Toole, E. T., McDonald, K. L., McIntosh, J. R., and Porter, M. E. (1992). Arrangement of inner dynein arms in wild-type and mutant flagella of Chlamydomonas. J. Cell Biol. 118, 1145-1162.

Matsuo, T., OK, Onai, K., Niwa, Y., Shimogawara, K., Ishiura, M. (2008). A systematic forward genetic analysis identified components of the Chlamydomonas circadian system. Genes Dev. 22, 918-930.

McVittie, A. (1972). Flagellum mutants of Chlamydomonas reinhardii. J. Gen. Microbiol. 71, 525-540.

Morita, Y., and Shingyoji, C. (2004). Effects of imposed bending on microtubule sliding in sperm flagella. Curr. Biol. 14, 2113-2118.

Myster, S. H., Knott, J. A., O’Toole, E., and Porter, M. E. (1997). The Chlamydomonas Dhc1 gene encodes a dynein heavy chain subunit required for assembly of the I1 inner arm complex. Mol. Biol. Cell 8, 607-620.

Myster, S. H., Knott, J. A., Wysocki, K. M., O'Toole, E., and Porter, M. E. (1999). Domains in the 1alpha dynein heavy chain required for inner arm assembly and flagellar motility in Chlamydomonas. J. Cell Biol. 146, 801-818.

Nicastro, D., Schwartz, C., Pierson, J., Gaudette, R., Porter, M. E., and McIntosh, J. R. (2006). The molecular architecture of axonemes revealed by cryoelectron tomography. Science 313, 944-948.

Nyarko, A., Hare, M., Hays, T. S., and Barbar, E. (2004). The intermediate chain of cytoplasmic dynein is partially disordered and gains structure upon binding to light-chain LC8. Biochemistry 43, 15595-15603.

Okagaki, T., and Kamiya, R. (1986). Microtubule sliding in mutant Chlamydomonas axonemes devoid of outer or inner dynein arms. J. Cell Biol. 103, 1895-1902.

Okita, N., Isogai, N., Hirono, M., Kamiya, R., and Yoshimura, K. (2005). Phototactic activity in Chlamydomonas'non-phototactic' mutants deficient in $\mathrm{Ca}^{2+}$-dependent control of flagellar dominance or in inner-arm dynein. J. Cell Sci. $118,529-537$.
Pazour, G. J., Agrin, N., Leszyk, J., and Witman, G. B. (2005). Proteomic analysis of a eukaryotic cilium. J. Cell Biol. 170, 103-113.

Pazour, G. J., Wilkerson, C. G., and Witman, G. B. (1998). A dynein light chain is essential for the retrograde particle movement of intraflagellar transport (IFT). J. Cell Biol. 141, 979-992.

Pazour, G. J., and Witman, G. B. (2000). Forward and reverse genetic analysis of microtubule motors in Chlamydomonas. Methods 22, 285-298.

Perrone, C. A., Myster, S. H., Bower, R., O'Toole, E. T., and Porter, M. E. (2000). Insights into the structural organization of the I1 inner arm dynein from a domain analysis of the 1beta dynein heavy chain. Mol. Biol. Cell 11, 2297-2313.

Perrone, C. A., Yang, P., O'Toole, E., Sale, W. S., and Porter, M. E. (1998). The Chlamydomonas IDA7 locus encodes a 140-kDa dynein intermediate chain required to assemble the I1 inner arm complex. Mol. Biol. Cell 9, 3351-3365.

Piperno, G., Ramanis, Z., Smith, E. F., and Sale, W. S. (1990). Three distinct inner dynein arms in Chlamydomonas flagella: molecular composition and location in the axoneme. J. Cell Biol. 110, 379-389.

Porter, M. E., Power, J., and Dutcher, S. K. (1992). Extragenic suppressors of paralyzed flagellar mutations in Chlamydomonas reinhardtii identify loci that alter the inner dynein arms. J. Cell Biol. 118, 1163-1176.

Porter, M. E., and Sale, W. S. (2000). The $9+2$ axoneme anchors multiple inner arm dyneins and a network of kinases and phosphatases that control motility. J. Cell Biol. 151, F37-F42.

Rozen, S., and Skaletsky, H. (2000). Primer3 on the WWW for general users and for biologist programmers. Methods Mol. Biol. 132, 365-386.

Silflow, C. D., Lefebvre, P. A., McKeithan, T. W., Schloss, J. A., Keller, L. R. and Rosenbaum, J. L. (1982). Expression of flagellar protein genes during flagellar regeneration in Chlamydomonas. Cold Spring Harb. Symp. Quant. Biol. 46, 157-169.

Sakakibara, H., Burgess, S., and Sakai, Y. (2006). Conformational changes of inner-arm dynein-f from Chlamydomonas coupled with phosphorylation of its intermediated chain IC138. Mol. Biol. Cell 17 (Suppl), abstract 211/B156. (CD-ROM)

Smith, E. F., and Sale, W. S. (1991). Microtubule binding and translocation by inner dynein arm subtype I1. Cell Motil. Cytoskeleton 18, 258-268.

Smith, E. F., and Yang, P. (2004). The radial spokes and central apparatus: mechano-chemical transducers that regulate flagellar motility. Cell Motil. Cytoskeleton 57, 8-17.

Williams, J. C., Roulhac, P. L., Roy, A. G., Vallee, R. B., Fitzgerald, M. C., and Hendrickson, W. A. (2007). Structural and thermodynamic characterization of a cytoplasmic dynein light chain-intermediate chain complex. Proc. Natl. Acad. Sci. USA. 104, 10028-10033.

Wirschell, M., Hendrickson, T., and Sale, W. S. (2007). Keeping an eye on I 1, I1 dynein as a model for flagellar dynein assembly and regulation. Cell Motil. Cytoskeleton 64, 569-579.

Wirschell, M., Zhao, F., Yang, C., Yang, P., Diener, D., Gaillard, A., Rosenbaum, J. L., and Sale, W. S. (2008). Building a radial spoke: flagellar radial spoke protein 3 (RSP3) is a dimer. Cell Motil. Cytoskeleton 65, 238-248.

Witman, G. B. (1986). Isolation of Chlamydomonas flagella and flagellar axonemes. Methods Enzymol. 134, 280-290.

Yanagisawa, H.-A., and Kamiya, R. (2004). A Tektin homologue is decreased in Chlamydomonas mutants lacking an axonemal inner-arm dynein. Mol. Biol. Cell 15, 2105-2115.

Yang, P., Diener, D. R., Rosenbaum, J. L., and Sale, W. S. (2001). Localization of calmodulin and dynein light chain LC8 in flagellar radial spokes. J. Cell Biol. 153, 1315-1326.

Yang, P., and Sale, W. S. (1998). The Mr 140,000 intermediate chain of Chlamydomonas flagellar inner arm dynein is a WD-repeat protein implicated in dynein arm anchoring. Mol. Biol. Cell 9, 3335-3349.

Yang, P., and Sale, W. S. (2000). Casein kinase I is anchored on axonemal doublet microtubules and regulates flagellar dynein phosphorylation and activity. J. Biol. Chem. 275, 18905-18912.

Zhang, Z., Futamura, M., Vikis, H. G., Wang, M., Li, J., Wang, Y., Guan, K. L., and You, M. (2003). Positional cloning of the major quantitative trait locus underlying lung tumor susceptibility in mice. Proc. Natl. Acad. Sci. USA 100, 12642-12647. 